\title{
CHALLENGING STUDENTS TO REDISCOVER ENGINEERING
}

\author{
Wayne H. Chang ${ }^{1}$, William D. Bishop ${ }^{2}$, Emily Peat ${ }^{1}$, and Eyram Dornor ${ }^{1}$ \\ ${ }^{1}$ Conrad School of Entrepreneurship and Business \\ ${ }^{2}$ Electrical and Computer Engineering Department \\ Faculty of Engineering, University of Waterloo \\ whchang@uwaterloo.ca,wdbishop@uwaterloo.ca
}

\begin{abstract}
The "Conrad Games in Engineering" encourages engineering students to develop entrepreneurship and innovation mindsets. Through a series of lunchtime sessions, the games re-awaken the fun and creativity that once encouraged students to pursue engineering. Students form teams to work on a design challenge that is introduced at the start of a session. Students accumulate points for their teams and houses, i.e. engineering departments. The point system is specifically designed to encourage students to take calculated risks and to challenge themselves. Design challenges are specifically chosen to be fun, engineering activities that last no more than 20 minutes. Special challenge teams, composed of faculty, alumni, and staff are invited to compete against the students for an additional dimension of risk and reward. Students apply the experiential learning cycle by revisiting challenges with additional criteria. Through this iterative approach, the games reinforce good engineering practice as well as group collaboration, communication, creativity and leadership skills.
\end{abstract}

Keywords: experiential learning, prototyping, games, entrepreneurial and innovation mindset, risk and reward

\section{INTRODUCTION}

To facilitate the themes of student engagement, and creativity and innovation in engineering education, we present an application learning mode through game play. These behaviour games as an extra-curricular activity is open to all undergraduate engineering students from all students' school terms years and all departments and programs. Competitors use good old-fashioned "roll up your sleeves" engineering design skills and ingenuity to quickly prototype a solution to a challenge. A points system is used to track competitors and their departments, i.e. houses throughout the school term, i.e. season. To build sense of identity and community, the students interact with classmates, other students across departments, faculty and staff members, as well as alumni. To encourage creativity and active prototyping, the game challenge themes are goal-driven with emphasis on limited resources $[1,2]$. These resource constraints include limited supply of materials in a kit format, time limit of only $20 \mathrm{~min}$ over specific lunch hour sessions, and maximum number of team members of 4 . This experiential learning mode of active experimentation is also a key indicator in the development of entrepreneurial and innovation mindset [3]. The game challenges are kept secret until the session starts so students have no opportunity to prepare for the challenges, and to create sense of positive energy, anticipation and intrigue. Due to the very limited time constraint (20min) and no temporal structure, the students have to create their own processes or how to structure their work and delegation of tasks very quickly to come up with a final prototype. This environment is designed to help the students learn and adapt from ambiguity and accepting certain levels of uncertainty $[4,5]$.

\section{METHODOLOGY}

All the game challenges have been developed into small kits of common stationary materials, balloons, reusable plastic cups, recycleable newspapers, etc. These kits are then re-used with added variations for future school term seasons. The goal of each of the challenges results in a final physical prototype or performance that is visual and can be measured objectively to award points to teams, and for teams to actively compare their prototypes to each other as they are in various stages of building prototype.

Teams have a total of 20min to read the Game Sheet 1page instructions, and using only the materials in their challenge kit, they build final prototype creation. When the time period ends, all the teams prototypes are evaluated to award points and select winners of the game challenge session. Example games are described below:

Marshmellow Tower (tallest)

-using limited spaghetti sticks, tape, string, marshmellows

Stacking Cup Pyramid (tallest)

-using limited cups, string, rubber band

Balloon Tower (tallest)

-using limited balloons, tape

Paper Rocket (accuracy)

-using limited paper, tape

WatKwiddich (WatSnitch launcher and catcher) 
-using limited newspaper, cups, tape

\section{RESULTS AND DISCUSSIONS}

All the various game challenges were simple reminders for the engineering students to reflect on their earlier times from high school science projects and fairs in creating similar things, and rediscover some of their esprit de corps and engineering ambitions. It provided a refreshing "pause" from curriculum courses or lab sessions and facilitated some creative outlets. Nearly all the prototypes that teams had built were very different in appearance, structure and size. Due to the 20min time constraint window, many experiments were done to try different process and many did not work the first cycle iteration. The goal was clear but the processes had to be created by each team. This focus on both goal and process as it relates to teaching engineering and students entrepreneurship is also described as one of the five principles in the Berkeley Method of Entrepreneurship (BMoE) and represented in Figure 1 [6]:

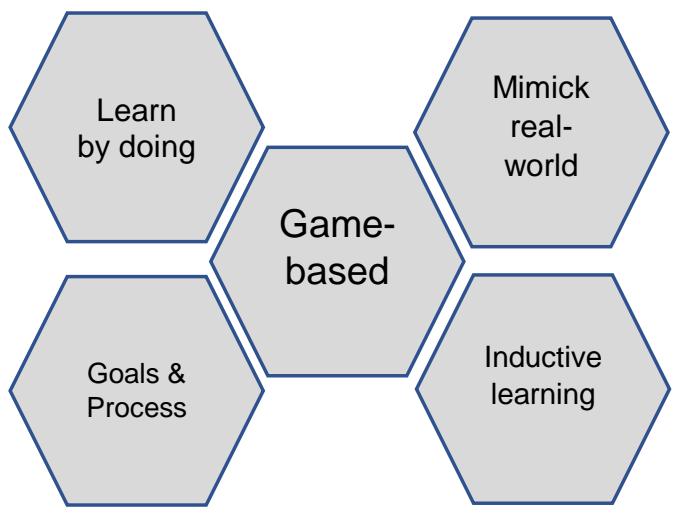

Figure 1. The five principles of BMoE

Most of these principles are present by curriculum design in the Faculty of Engineering disciplines and programs at the University of Waterloo, especially Learning by Doing as experiential learning in the form of required co-op program workterms. However, the adoption here of the described game-based learning mode in this short format of $20 \mathrm{~min}$ series of 3 to 4 game challenges each school term is an experiment to reinforce team dynamics, leadership and creativity in problem-solving with very limited resources (constraints with time, materials, people). During the term season, a Points Leader Board is visible to all competitors to see their standings both individually and for their department houses. At the end of the season, prizes are awarded and competitors are invited to submit new ideas for game challenge themes for future seasons as a form of crowdsourcing new themes and variations of current ones.
Three key insights of the BMoE [7]:

- Mindset is of great importance for entrepreneurs and should therefore be included in entrepreneurship education.

- The mindset of successful entrepreneurs can largely be captured by a set of identified behavioral patterns.

- Games and debriefing sessions are suitable tools for teaching and learning mindset. They provide the students with a mean for exploring their own mindset and behaviour, and also give a starting point for a possible change.

From a behaviour development perspective, this game environment also promotes many of the CEAB 12 Graduate Attributes [8], e.g. Problem analysis, Design, Team work, and Communications. In regular instances, some of the teams welcomed new team members at the session for the very first time and had to quickly develop rapport together. Some teams actively compared and contrasted their designs to others team while still in developing their own prototype as part of vicarious learning opportunities. The session environment was energetic and lively. This setting was very conducive to rapid prototyping and goal-focussed.

To support the engineering community and identity, one memorable highlight example was the Halloween Day 2018 game challenge session, and students dressed up in costumes. The Dean of Engineering made a surprise appearance dressed as Darth Vader from the Star Wars movie series.

\section{CONCLUSIONS}

A behaviour game-based learning mode has been successfully implemented as an extra curricular activity to enhance development of entrepreneurial and innovation mindset. As demonstrated by series of game challenge themes:

- Creativity from resource constraints,

- Focus on goals and processes,

- Decision-making with respect to Risk vs Reward options. These games serve as a learning tool to help students rediscover some of their engineering aspirations through fast prototype development in a fun and creative environment. The much larger impact is to engage our school's Engineering community of students, faculty, staff and alumni.

\section{FUTURE WORK}

The following descriptions for consideration as next cycles of learning and iterations for future term seasons:

- Risk vs Reward incentives options for further decisionmaking with Challenge Teams, 
- Integrated games element as part of curricula course designs with points system,

- An end of term season reflection survey to provide feedback for specific indicators related to mindset and behavioural development, and community engagement and alumni identity.

\section{Acknowledgements}

Funding and support for this project was provided by the Conrad School of Entrepreneurship and Business, Thomson Reuters corporate sponsorship, the Faculty of Engineering Alumni Advancement Office, and the Dean of Engineering Office, the University of Waterloo.

\section{References}

[1] Tom Wujec, "Build a tower, build a team", TED2010 Talk, 2010, February.

https://www.ted.com/talks/tom_wujec_build_a_tower?langu $\underline{\text { age }=e n}$
[2] E. Noyes, "Teaching Entrepreneurial Action Through Prototyping: The Prototype-It Challenge", Entrepreneurship Education and Pedagogy, 2018, Volume I, 118-134

[3] R. Gemmell, "Learning styles of entrepreneurs in knowledgeintensive industries", International Journal of Entrepreneurial Behaviour and Research, 2017, Volume 23 (3), 446-464

[4] H. Lifshitz-Assaf, S. Lebovitz, L. Zalman, "The Art of Balancing Autonomy and Control", MIT Sloan Management Review, 2018, December 13

[5] L. Bosman and S. Fernhaber, Teaching the Entrepreneurial Mindset to Engineers, International Publishing AG, 2018, $142 \mathrm{pp}$.

[6] https://scet.berkeley.edu/berkeley-method-entrepreneurship/

[7] Charlotta Johnsson, Ikhlaq Sidhu, Mari Suoranta, Ken Singer, "Guiding Students towards an Entrepreneurial Mindset", in Institute for Higher Education Learning, Symposium, Riga, Latvia, May 2017.

[8] https://engineerscanada.ca/sites/default/files/GraduateAttributes.pdf 